\title{
White Wine
}

National Cancer Institute

\section{Source}

National Cancer Institute. White Wine. NCI Thesaurus. Code C84877.

An alcoholic beverage made from fermented white grapes with potential orexigenic activity. Although not well understood, the mechanism for white wine's potential orexigenic activity may be due, in part, to its alcohol content and may involve alterations in neurotransmitter and hormone activities related to appetite regulation. 